\title{
0 CONCEITO DE INTERDISCIPLINARIDADE E DE ABORDAGEM INTERDISCIPLINAR PARA PROFESSORES DE CIÊNCIAS EM PROCESSO DE FORMAÇÃO CONTINUADA ${ }^{1}$
}

\author{
THE CONCEPT OF INTERDISCIPLINARITY AND INTERDISCIPLINARY APPROACH FOR \\ SCIENCE TEACHERS IN CONTINUOUS TRAINING PROCESS
}

\author{
ANA PAULA DAMEÃO² \\ PATRÍCIA SANDALO PEREIRA ${ }^{3}$ \\ PAULO RICARDO DA SILVA ROSA ${ }^{4}$ \\ NÁDIA CRISTINA GUIMARÃES ERROBIDART ${ }^{5}$
}

\section{RESUMO}

Neste trabalho apresentamos os resultados de pesquisa que teve como sujeitos os acadêmicos do curso de Doutorado em Ensino de Ciências da UFMS. Analisamos a concepção que os acadêmicos têm sobre interdisciplinaridade e qual a percepção que têm sobre a viabilidade de desenvolver atividades interdisciplinares na escola. Os dados foram obtidos a partir das respostas dadas a um questionário, após categorizadas como asserções de conhecimento ou asserções de valor, foram analisadas em busca do conceito de interdisciplinaridade presente e do viés, positivo, negativo ou neutro, em relação ao desenvolvimento de atividades interdisciplinares na escola. 0 método utilizado foi 0 da llha de Racionalidade Interdisciplinar de Fourez. Os resultados obtidos mostram que a concepção apresentada pelos sujeitos em relação ao conceito de interdisciplinaridade é próxima da definição de multidisciplinaridade. Quanto ao viés, a maioria dos sujeitos apresentou um viés positivo em relação ao desenvolvimento de atividades interdisciplinares na escola.

Palavras-chave: Ilha de Racionalidade Interdisciplinar, Formação de professores, Ensino de Ciências.

\section{ABSTRACT}

In this work we present the results of research that had as subjects the students of the PhD course in Science Teaching at UFMS. We analyze the conception that academics have about interdisciplinarity and what their perception is about the feasibility of developing interdisciplinary activities at school. The data were obtained from the answers given to a questionnaire, after being categorized as knowledge assertions or value assertions, were analyzed in search of the concept of present interdisciplinarity and the bias, positive, negative or neutral, in relation to the development of interdisciplinary activities at school. The method used was Fourez's Interdisciplinary Rationality Island. The results obtained show that the conception presented by the subjects in relation to the concept of interdisciplinarity is close to the definition of multidisciplinarity. As for bias, most subjects showed a positive bias in relation to the development of interdisciplinary activities at school.

Keywords: Island of Interdisciplinary Rationality; Teacher training; Science teaching.

\footnotetext{
10 presente trabalho foi realizado com apoio da Universidade Federal de Mato Grosso do Sul - UFMS.

2 Doutoranda em Ensino de Ciências do Instituto de Física da Universidade Federal do Mato Grosso do Sul (INFI/UFMS). Bolsista da Coordenação de Aperfeiçoamento de Pessoal de Nível Superior - Brasil (Capes) - Código de Financiamento 001. E-mail: apdameao@gmail.com. https:// orcid.org/0000-0001-7348-0111

3 Doutora em Educação Matemática (UNESP/Rio Claro - SP). Docente do Instituto de Matemática da Universidade Federal de Mato Grosso do Sul (INMA/UFMS). E-mail: patricia.pereira@ufms.br. Orcid: https://orcid.org/0000-0002-7554-0058

4 Doutor em Ciências (UFRGS/Porto Alegre - RS). Docente Titular Aposentado do Instituto de Física da Universidade Federal do Mato Grosso do Sul (INFI/UFMS). E-mail: paulo.rosa@ufms.br. Orcid: https://orcid.org/0000-0001-5418-8596

5 Doutora em Educação (UFMS/Campo Grande - MS). Docente do Instituto de Física da Universidade Federal do Mato Grosso do Sul (INFI/UFMS). E-mail: nadia.guimaraes@ufms.br. Orcid: https://orcid.org/0000-0002-7240-5723
} 


\section{INTRODUÇÃO}

A formação de professores, entendida como uma formação específica para a docência, tem início no Brasil em meados do século XIX, com o Decreto $n^{0} 10$ de 1835, com a criação da Escola Normal, cuja finalidade era formar professores para o ensino das "primeiras letras", o que seria hoje as primeiras séries do Ensino Fundamental (PRADO, 2020).

Na década de 1930, a formação de professores para o ensino secundário consistia na obtenção da licenciatura a partir da formação dos bacharéis. Ou seja, para a obtenção da habilitação para lecionar, no que conhecemos atualmente como ensino médio, os bacharéis cursavam um ano de disciplinas na área de educação, no que ficou conhecido como modelo $3+1$. Este modelo de formação estendeu-se para os cursos de Pedagogia habilitando os bacharéis em educação para lecionar nas Escolas Normais, no Ensino Médio e nas séries de $1^{\text {a }}$ a $4^{\mathrm{a}}$ do ensino fundamental (GATTI, 2010).

Na década de 1970, com a implementação da Lei $n^{0} 5.692 / 71$ (BRASIL, 1971) que introduziu mudanças no sistema de educação do Brasil, a Escola Normal passa a ser uma habilitação do $2^{\circ}$ grau $^{6}$. Posteriormente, a Lei de Diretrizes e Bases da Educação Nacional (LDB) - Lei nº 9.394/96 (BRASIL, 1996) determina que a formação de professores para todos os níveis deve ser realizada em nível superior. Em 2002, de modo a regulamentar o disposto na LDB, o Conselho Nacional de Educação estabelece as Diretrizes Curriculares Nacionais para a formação de professores (BRASIL, 2002) e, posteriormente, foram modificadas em 2015 (BRASIL, 2015). Estas resoluções estabelecem que as Licenciaturas devem ser ofertadas por Instituições de Educação Superior (IES). Os cursos de Pedagogia, após a regulamentação da Resolução no 1 de 15/05/2006 (BRASIL, 2006), passam a formar professores para o exercício do magistério na educação infantil, nos anos iniciais do Ensino Fundamental e no Ensino Médio na modalidade Normal (GATTI, 2010).

Por outro lado, a reforma universitária de 1968 - Lei n 5.540, de 28 de novembro de 1968 (BRASIL, 1968) e 0 Decreto Lei $n^{\circ}$ 477, de 26 de fevereiro de 1969 (BRASIL, 1969) estabeleceu a estrutura departamental nas universidades brasileiras, agrupando departamentos afins em unidades administrativas de diferentes naturezas (Institutos, Faculdades, Centros etc.). Nesta estrutura as disciplinas dos cursos são ofertadas pelos departamentos, independentemente de qual seja a vinculação do curso. Assim, por exemplo, as disciplinas de Cálculo ofertadas aos cursos de Licenciatura em Física ou Química são ofertadas pelo Departamento de Matemática do Instituto de Matemática ou Centro de Ciências Exatas, enquanto a disciplina de Didática é ofertada pela Faculdade de Educação. Supõe-se que o Projeto Pedagógico do Curso propicie momentos de integração entre estes diferentes saberes disciplinares. No entanto, segundo Gatti (2010, p. 1358), "0 que se verifica é que a formação de professores para a educação básica é feita, em todos os tipos de licenciatura, de modo fragmentado entre as áreas disciplinares e níveis de ensino".

Apesar de terem sido previstos e implementados em algumas instituições, os Institutos de Normais Superiores não prosperaram e, no Brasil,

6 Anteriormente a esta lei, o ensino secundário era formado pelo Ensino Normal (formador de professores do Ensino Primário e de caráter terminal), o Ensino Científico (preparatório às carreiras em nível superior das Ciências da Natureza e da Terra e áreas biológicas) e 0 Ensino Clássico (preparatório às carreiras das Ciências Humanas e Sociais). Os ciclos anteriores ao secundário eram o Primário (5 anos) e 0 Ginasial (4 anos). Por esta lei, os Ensino Primário e Ginasial foram agrupados em um único ciclo, o Primeiro Grau, com 8 anos. 0 Ensino Secundário passou a chamar-se Segundo Grau, com caráter profissionalizante. 
[...] as instituições de ensino superior não contam com uma faculdade ou instituto próprio para a formação desses profissionais, com uma base comum formativa, como observado em outros países, onde há centros de formação de professores englobando todas as especialidades, com estudos, pesquisas e extensão relativos à atividade didática e às reflexões e teorias a ela associadas (GATTI, 2010, p. 1358).

Por outro lado, a estrutura da escola reproduz como disciplinas escolares a estrutura das disciplinas científicas (CHERVEL, 1988), reproduzindo no campo escolar a fragmentação observada na própria estrutura do conhecimento científico. Este ensino fragmentado experienciado pelos professores durante sua graduação e que é reproduzido nas escolas favorece que, em suas práticas escolares, os professores repliquem no ensino básico a fragmentação oriunda da hiperespecialização das disciplinas. De fato, as disciplinas não são unicamente responsáveis por esta lógica de reprodução. Outro fator que devemos observar é o processo sócio-histórico vivido pela sociedade na qual estamos inseridos. A maneira como se desenvolveu ao longo dos séculos, passando do modo de produção de subsistência para produção em larga escala e de consumo rápido, teve impacto no desenvolvimento do conhecimento científico, contribuindo para a fragmentação do conhecimento (TONET, 2016). Esta produção em larga escala somente foi possível pela fragmentação do trabalho ${ }^{8}$.

Diante disso, Pretto (2017)

[...] defende a necessidade de uma mudança curricular nos cursos de formação de professores na qual se desenvolvam estudos comprometidos com a contemporaneidade de forma coletiva, envolvendo todos os alunos de licenciatura da instituição, promovendo interações entre licenciandos de diferentes áreas do conhecimento, levando-os a vivenciar na universidade um ambiente interdisciplinar que os prepare para agir de modo não fragmentado ao atuarem nas escolas como profissionais da educação (apud SANTOS et al., 2019, p. 3).

Quando pensamos na interdisciplinaridade na escola é interessante observar o que os documentos oficiais trazem. Nesse sentido, buscamos a palavra interdisciplinaridade e seus correlatos em vários documentos oficiais: as Diretrizes Curriculares Nacionais para a Formação Inicial de Professores, as Diretrizes Curriculares Nacionais Gerais para a Educação Básica, a Base Nacional Curricular Comum para o Ensino Médio, a Lei de Diretrizes e Bases da Educação Nacional e os Instrumentos de Avaliação de Curso e Institucional do Instituto Nacional de Estudos e Pesquisas Educacionais Anísio Teixeira (Inep). 0 resultado desta busca pode ser visto no Quadro 1.

7 Aí compreendida a própria universidade e os cursos de formação de professores.

80 caso mais clássico é 0 do aperfeiçoamento da linha de produção para fabricação de automóveis por Henry Ford. 
Quadro 1 - Frequência da palavra interdisciplinaridade e seus correlatos em alguns documentos oficiais da Educação Nacional.

\begin{tabular}{|l|c|}
\hline \multicolumn{1}{|c|}{ Documentos } & Frequência \\
\hline Lei de Diretrizes e Bases da Educação Nacional (BRASIL, 1996) & 00 \\
\hline $\begin{array}{l}\text { Diretrizes Curriculares Nacionais para a formação inicial em nível superior (cursos de licenciatura, cursos de formação } \\
\text { pedagógica para graduados e cursos de segunda licenciatura) e para a formação continuada (BRASIL, 2015). }\end{array}$ & 22 \\
\hline Diretrizes Curriculares Nacionais Gerais para a Educação Básica (BRASIL, 2010) & 08 \\
\hline Base Nacional Comum Curricular para o Ensino Médio (BRASIL, 2018) & 01 \\
\hline $\begin{array}{l}\text { Instrumento de Avaliação de Cursos de Graduação - IACG/Inep (Estrutura Curricular, Experiência profissional do docente) } \\
\text { (BRASIL, 2017a) }\end{array}$ & 15 \\
\hline $\begin{array}{l}\text { Instrumento de Avaliação Institucional Externa - IAIE/Inep (PDI, planejamento didático instrucional e política de ensino } \\
\text { de graduação e de pós-graduação) (BRASIL, 2017b) }\end{array}$ & 04 \\
\hline
\end{tabular}

Fonte: Dados da pesquisa.

Excetuando os documentos do Inep (BRASIL, 2017), nos outros a palavra interdisciplinaridade e seus correlatos não apresentam definição, porém aparecem ligadas à formação interdisciplinar, ao trabalho coletivo e interdisciplinar, aos conhecimentos interdisciplinares, à abordagem interdisciplinar, projetos interdisciplinares, entre outros.

Nos documentos do Inep (BRASIL, 2017), a definição da palavra interdisciplinaridade aponta para:

Concepção epistemológica do saber na qual as disciplinas são colocadas em relação, com o objetivo de proporcionar olhares distintos sobre o mesmo problema, visando a criar soluções que integrem teoria e prática, de modo a romper com a fragmentação no processo de construção do conhecimento (BRASIL, 2017, p. 40).

Uma contradição que podemos observar nos documentos referidos anteriormente, principalmente nas Diretrizes Nacionais para a Formação Inicial de Professores (BRASIL, 2015), é a ausência de orientações da formação para a interdisciplinaridade. Nos documentos não encontramos nenhuma orientação ou preocupação expressa com a formação de professores que sejam capazes de desenvolver o ensino interdisciplinar proposto para a Educação Básica.

Por outro lado, encontramos na literatura diferentes definições para o termo interdisciplinaridade. Por exemplo:

0 termo interdisciplinar pode ser caracterizado como o nível em que a colaboração entre as diversas disciplinas ou entre os setores heterogêneos de uma mesma ciência conduz a interações propriamente ditas, isto é, a uma certa reciprocidade nos intercâmbios, de tal forma que, no final do processo interativo, cada disciplina saia enriquecida (JAPIASSU, 1976, p. 75).

A interdisciplinaridade é percebida como uma prática essencialmente, isto é, como uma negociação entre diferentes pontos de vista, para finalmente se decidir como uma representação considerada adequada, em vista de uma ação (FOUREZ, 1998, p. 137). 
0 termo interdisciplinaridade evoca um espaço comum, um fator de coesão entre saberes diferentes. Cada qual aceita fazer um esforço fora do seu domínio e da sua linguagem técnica própria, para se aventurar num domínio de que não é proprietário exclusivo (MAINGAIN; DUFOUR; FOUREZ, 2008, p. 69).

[...] não existe uma definição única possível para esse conceito, senão muitas, tantas quantas sejam as experiências interdisciplinares em curso no campo do conhecimento (THIESEN, 2008, p. 547).

Em nosso entendimento, a interdisciplinaridade é a mobilização de forma integrada de diferentes conhecimentos disciplinares para a solução de um problema complexo, a qual pode ser realizada mediante o emprego do Método de construção de uma llha de Racionalidade Interdisciplinar, esquematizada na Figura 1.

Figura 1 - Método de construção de uma ilha de Racionalidade Interdisciplinar

\begin{tabular}{|c|c|}
\hline \multicolumn{2}{|c|}{ DEFINIR UM PROBLEMA COMPLEXO } \\
\hline $\begin{array}{l}\text { NEGOCIAR E PROBLEMATIZAR } \\
\text { O PROCESSO } \\
\text {-Formular a problemática definindo do que se trata; } \\
\text { - Especificar o projeto delimitando o contexto, as } \\
\text { finalidades, os destinatários e a forma de } \\
\text { materialização da IRI }\end{array}$ & $\begin{array}{l}\text { FAZER EMERGIR O CLICHÊ } \\
\text { Explicitar o ponto de vista do qual se inicia o } \\
\text { processo, estabelecendo um inventário das } \\
\text { representações dos construtores sobre a } \\
\text { situação complexa }\end{array}$ \\
\hline $\begin{array}{l}\text { ESTABELECER } \\
\text { - Emprego de grelhas de análise elaboradas com } \\
\text { como normas e valores } \\
\text { - Identificar as caixas pretas, as fontes de conhecime } \\
\text { - Abrir as caixas pretas, selecionar conhecimentos co }\end{array}$ & $\begin{array}{l}\text { NORAMA } \\
\text { nos destinatários, em aspectos condicionantes } \\
\text { lisciplinares e não disciplinares } \\
\text { erentes pontos de vista relevantes }\end{array}$ \\
\hline
\end{tabular}

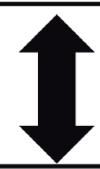

\section{PROCEDER AS INVESTIGAÇÕES}

- Selecionar os pontos de vista mais relevantes para compor a síntese parcial;

Delimitar a amplitude e profundidade dos conhecimentos que serão apresentados na síntese final

\section{CONSTRUIR UMA REPRESENTAÇÃO}

INTERDISCIPLINAR

Elaborar a síntese final que materializa a Ilha de Racionalidade Interdisciplinar

Validar a IRI

Testar a representação complexa e efetuar possíveis ajustes para aplicá-la em outros contextos

Fonte: (MAINGAIN; DUFOUR; FOUREZ, 2008). 
Devemos salientar que as várias definições utilizadas para o termo interdisciplinaridade, por vezes, causam confusão em parte dos professores, principalmente com os termos multidisciplinaridade, pluridisciplinaridade e transdisciplinaridade. Cabe aqui uma breve discussão em relação a estes últimos termos.

De acordo com Rech e Rezer (2020, p. 472):

[...] Multidisciplina: Justaposição de disciplinas diversas, desprovidas de relação aparente entre elas. Ex.: música + matemática + história; Pluridisciplina: Justaposição de disciplinas mais ou menos vizinhas nos domínios do conhecimento. Ex.: domínio científico: matemática + física; [...] Transdisciplina: axiomática comum a um conjunto de disciplinas (ex. Antropologia, considerada 'a ciência do homem e de suas obras', segundo Linton).

Desta maneira, entendemos a multidisciplinaridade como justaposição de disciplinas, sem finalidade previamente determinada; a pluridisciplinaridade como a justaposição de disciplinas em função de uma finalidade e a transdisciplinaridade como compartilhamento de conceitos entre disciplinas.

Contudo, como preparar os professores para a interdisciplinaridade? Para isso, a própria formação docente deve ser repensada, o que nos leva a questionar: como formar professores para 0 desenvolvimento de atividades interdisciplinares? Esta questão possui certa complexidade, pois, como apontado anteriormente, os próprios cursos de formação de professores são organizados de forma disciplinar, o que compromete o desenvolvimento de atividades interdisciplinares na educação básica e superior.

Como observado anteriormente, a formação de professores para trabalhar interdisciplinarmente é uma questão aberta nos documentos oficiais. Neste trabalho, partimos do pressuposto que preparar professores para o fazer interdisciplinar somente é possível pelo uso da própria interdisciplinaridade, rompendo com a fragmentação curricular, o que nos leva a abrir mão de um ambiente de ensino tradicional baseado na racionalidade técnica, para lançar o olhar para um ensino interdisciplinar baseado em uma metodologia que proporcione a busca para solução de problemas complexos, problemas estes que por muitas vezes são oriundos de uma demanda social vivida.

Estes fatores nos inspiram a repensar a estrutura curricular da formação de professores, ou seja, nos leva a pensar na necessidade de mudança no currículo da formação de professores e repensar a estrutura do ambiente no qual está inserida. Possibilitar ambiente de ensino interdisciplinar para professores pode ser caminho para o trabalho interdisciplinar no ensino básico.

Outro problema, entretanto, é a formação continuada dos professores. Para estes, a reestruturação curricular dos cursos de formação de professores não seria uma solução; e outras formas de capacitá-los para a interdisciplinaridade devem ser buscadas.

Todavia, antes de qualquer proposta formativa ou de modificação curricular, é preciso entender 0 que os docentes em serviço pensam sobre a interdisciplinaridade e o fazer interdisciplinar na escola.

Neste trabalho, apresentamos os resultados de uma pesquisa preliminar a um projeto de formação continuada para a interdisciplinaridade que teve como proposta 0 estudo do conceito de interdisciplinaridade e de abordagem interdisciplinar entre professores que ensinam ciências cursando um curso de doutorado. 0 objetivo é o de desvendar o que professores em serviço, mas cursando formação continuada, pensam sobre a interdisciplinaridade e sobre o fazer interdisciplinar na escola.

Nas seções seguintes apresentamos a metodologia empregada no trabalho e os resultados obtidos. 


\section{METODOLOGIA}

Esta pesquisa é classificada como empírica e qualitativa. As atividades foram desenvolvidas durante a aula da disciplina de Metodologia de Pesquisa Qualitativa, ofertada no Programa de Pós-Graduação em Ensino de Ciências (PPEC) da Universidade Federal do Mato Grosso do Sul, no primeiro semestre de 2019. Os participantes da pesquisa foram quatorze acadêmicos do curso de Doutorado em Ensino de Ciências do PPEC/UFMS, sendo oito com formação em biologia, cinco em química e um em geografia. Dois acadêmicos, um com formação em geografia e outro em biologia, também possuem graduação em pedagogia. Dos quatorze acadêmicos, sete atuam como professores e dois como coordenadores pedagógicos da rede de ensino básico, dois no ensino superior, um como técnico de assuntos educacionais no ensino superior e um atua como consultor para assuntos indígenas.

Para realizar as atividades, buscamos utilizar como base a proposta metodológica descrita por Gérard Fourez. Este autor aparece nesse contexto contribuindo com inúmeros trabalhos sobre a interdisciplinaridade e o fazer interdisciplinar. Uma de suas contribuições para a aplicação da interdisciplinaridade no ambiente educacional é o conceito de llha de Racionalidade Interdisciplinar. Sua proposta metodológica oferece um caminho para trabalhar ações interdisciplinares no ambiente educacional desde a Educação Básica até a formação continuada de professores. A metodologia proposta por ele consiste em um conjunto de etapas descritas da seguinte maneira: a Fase Clichê, o Panorama Espontâneo que consiste em ida a campo, a abertura de caixas pretas, seja de forma independente ou pela consulta a especialistas, a descoberta de "princípios disciplinares", esquematização global e, por fim, a Síntese da llha de Racionalidade Interdisciplinar produzida (DAMEÃO; ROSA; ERROBIDART, 2017).

A atividade com os professores foi dividida em dois momentos. No primeiro momento foi solicitado a eles que produzissem um texto respondendo à seguinte pergunta: 0 que é interdisciplinaridade em minha opinião? Para desenvolver esta atividade foi fornecido aos professores um roteiro de atividades intitulado: $\mathbf{0}$ que interdisciplinaridade significa para mim?

Com a finalidade de orientar os participantes, neste roteiro foram apresentados os seguintes questionamentos: $\mathbf{0}$ termo interdisciplinaridade tem sido muito usado no campo educacional. Por exemplo, nas Diretrizes Nacionais para Formação de Professores para a Educação Básica este termo aparece muitas vezes. Gostaríamos que você descrevesse abaixo o que este termo significa para você (Q1). Ao longo de sua vida escolar e acadêmica, você acredita que já vivenciou alguma situação na qual a interdisciplinaridade tenha sido a abordagem escolhida? Caso tenha vivenciado, você poderia nos descrever esta ou estas situações? (Q2). Os professores tiveram 15 minutos para realizarem esta atividade.

Observe-se que esta produção escrita corresponde à Fase Clichê descrita anteriormente. Esta atividade foi seguida pela leitura coletiva de um texto abordando as conceituações de disciplina, multi, pluri, inter e transdisciplinaridade.

No segundo momento foi apresentado um filme abordando a temática interdisciplinaridade e uma apresentação sobre o método proposto para a construção da llha de Racionalidade Interdisciplinar.

\section{PROCEDIMENTOS DE ANÁLISE DE DADOS}

Para fins de análise, nossa atenção está sobre a produção escrita às quais foram transcritas manualmente mantendo as características da grafia de cada participante. Procuramos, nessas produções, identificar qual o conceito que os participantes possuíam naquele momento em relação à 
interdisciplinaridade. Os discursos produzidos pelos professores foram divididos em unidades de análise. Estas unidades de análise foram as sentenças presentes nos discursos. Estas sentenças foram classificadas como sendo de dois tipos: asserções de valor e asserções de conhecimento. De acordo com Rosa (2015, p. 217),

As asserções de Conhecimento expressam fatos tidos como verdadeiros: 0 Sol gira em torno do centro da Via Láctea. Por outro lado, as Asserções de Valor expressam opiniões dos sujeitos que as emitem, normalmente sobre aspectos morais e éticos: foi bom calcular o número Pi até a milionésima casa.

Uma vez classificadas, as asserções de conhecimento foram analisadas em busca do conceito de interdisciplinaridade presente e sua aderência aos conceitos do referencial teórico utilizado nesta pesquisa. Já as asserções de valor (subjetividades) expressam atitudes positivas ou negativas dos professores em relação à interdisciplinaridade (ROSA , 2015).

\section{RESULTADOS}

Com base nas transcrições das respostas obtidas na atividade escrita dos participantes, apresentamos os resultados de nossa análise distribuídos por professor.

Figura 2 - Transcrição do professor 1 (P1)

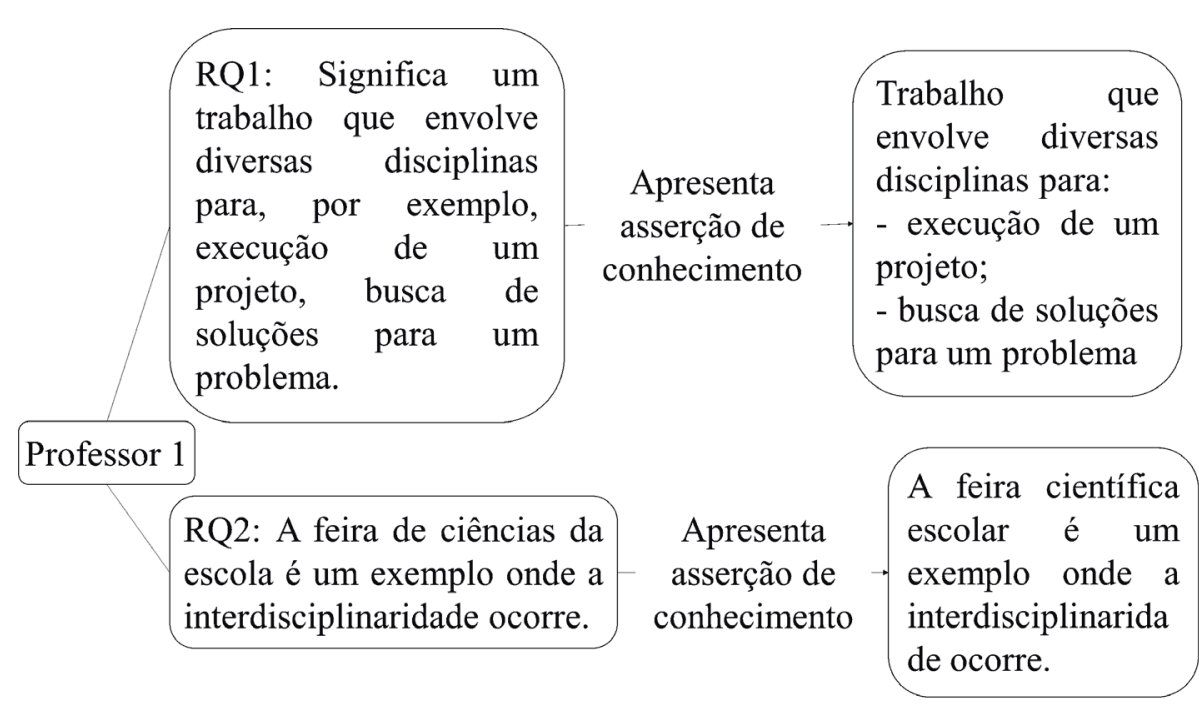

Fonte: Elaborado pelos autores

Na Q1 o sujeito associa o termo a uma atividade que envolve diversas disciplinas com um objetivo em mente: desenvolvimento de um projeto ou a busca de solução para um problema com foco nas disciplinas como fonte do conhecimento necessário. Apresenta convergência para 0 termo interdisciplinaridade, ou seja, há um elemento agregador para a reunião das disciplinas. 
Na Q2 relata ter vivenciado. Apesar de apresentar o conceito de interdisciplinaridade próximo do nosso referencial o exemplo apresentado não corresponde a uma atividade interdisciplinar no sentido estrito, deste modo não apresenta nenhum viés. Assim, em nenhuma das duas respostas 0 sujeito apresentou viés em relação à interdisciplinaridade.

Figura 3 - Transcrição do professor 2 (P2)
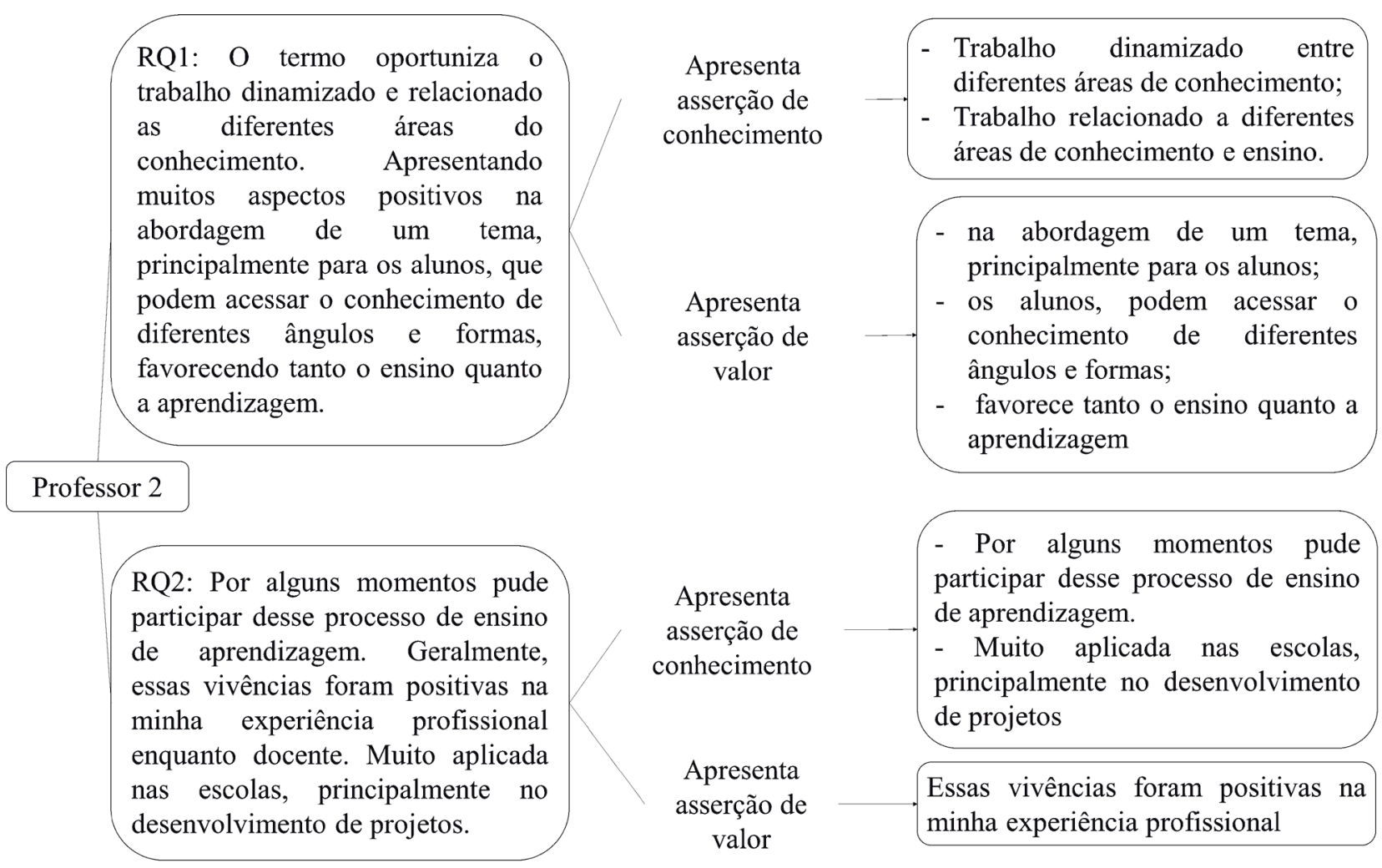

Fonte: Elaborado pelos autores

Na Q1 o sujeito associa o termo a uma atividade que envolve diversas disciplinas, ou seja, não há referência à necessidade de um objetivo a ser alcançado. Deste modo, apresenta um viés positivo em relação à interdisciplinaridade, porém indica convergência ao termo multidisciplinaridade, pois não há um elemento agregador para a reunião das diferentes disciplinas.

Na Q2 relata ter vivenciado, mas não descreve situações específicas. Embora fale dos projetos, não explicita se vivenciou ou não algum deles, assim apresenta viés positivo (vivências foram positivas). 0 sujeito mostra uma noção de multidisciplinaridade, mas não detalha o que seriam os projetos e porque eles seriam interdisciplinares indicando um viés positivo. Assim, nas duas questões o sujeito apresentou um viés positivo em relação à interdisciplinaridade. 
Figura 4 - Transcrição do professor 3 (P3)

\begin{tabular}{|c|c|c|}
\hline $\begin{array}{l}\text { RQ1: Quando estão envolvidos } \\
\text { duas ou mais áreas do } \\
\text { conhecimento. }\end{array}$ & $\begin{array}{c}\text { Apresenta } \\
\text { Asserção de } \\
\text { conhecimento }\end{array}$ & $\begin{array}{l}\text { envolvidos duas ou mais áreas do } \\
\text { conhecimento }\end{array}$ \\
\hline \multicolumn{3}{|l|}{ Professor 3} \\
\hline $\begin{array}{l}\text { RQ2: Como trabalho e vivencio a } \\
\text { educação indígena isto ocorre } \\
\text { bastante. Na faculdade também } \\
\text { tive várias disciplinas com } 3 \text { ou } \\
\text { mais professores de áreas } \\
\text { diferentes }\end{array}$ & $\begin{array}{c}\text { Apresenta } \\
\text { asserção de } \\
\text { conhecimento }\end{array}$ & $\begin{array}{l}\text { - Como trabalho e vivencio a } \\
\text { educação indígena isto ocorre } \\
\text { bastante. } \\
\text {-Na faculdade também tive várias } \\
\text { disciplinas com } 3 \text { ou mais } \\
\text { professores de áreas diferentes }\end{array}$ \\
\hline
\end{tabular}

Fonte: Elaborado pelos autores

Na Q1 o sujeito associa o termo a uma atividade que envolve diversas disciplinas, ou seja, não há referência à necessidade de um objetivo a ser alcançado o que indica convergência ao termo multidisciplinaridade.

$\mathrm{Na}$ Q2 relata ter vivenciado, mas não explicita quais seriam estas situações. Os exemplos apresentados pelo sujeito são coerentes com a visão que tem sobre interdisciplinaridade como uma atividade multidisciplinar não indicando nenhum viés. Deste modo, nas duas respostas o sujeito não apresentou viés em relação à interdisciplinaridade.

Figura 5 - Transcrição do professor 4 (P4)

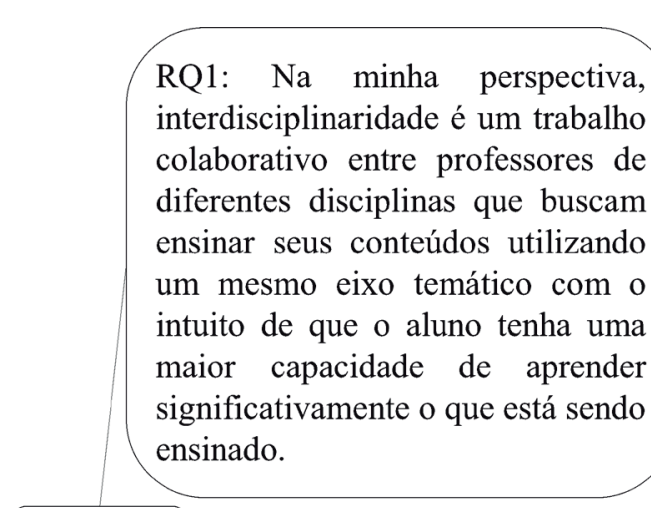

Professor 4

RQ2: Sim vivi, não foi efetivo Talvez tenha vivido tentativas rasas.

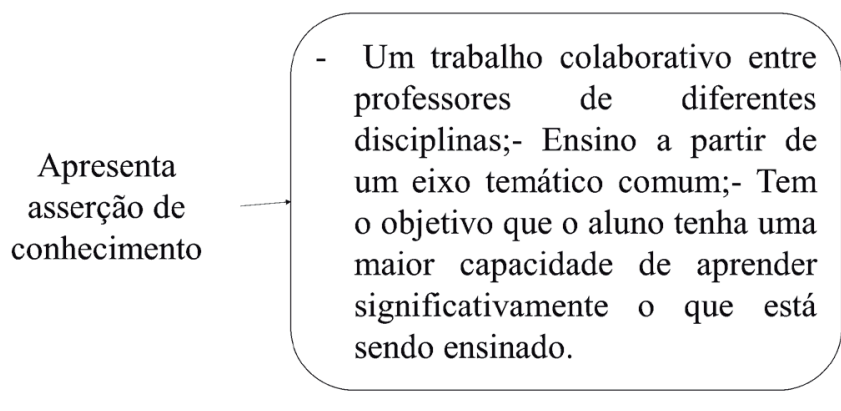

Apresenta asserção de conhecimento

$$
\text { - Sim, vivi. }
$$

$$
\begin{aligned}
& \text { Apresenta } \\
& \text { asserção de } \\
& \text { valor }
\end{aligned} \longrightarrow \begin{aligned}
& - \text { não foi efetivo. } \\
& - \text { Talvez tenha vivido tentativas } \\
& \text { rasas. }
\end{aligned}
$$

Fonte: Elaborado pelos autores 
Na Q1 o sujeito associa o termo a uma atividade que envolve diversas disciplinas, ou seja, há referência a um eixo temático comum, mas não há referência a um objetivo a ser alcançado. A aprendizagem referenciada é disciplinar, "o que está sendo ensinado" indicando convergência para o termo multidisciplinaridade.

Na Q2 relata ter vivenciado, mas não explicita quais seriam estas situações. 0 sujeito mostra um viés negativo (não foi efetivo; tentativas rasas). Não explicitou quais seriam as experiências que teve de natureza interdisciplinar indicando um viés negativo. Assim, apresenta um viés negativo em relação à interdisciplinaridade.

Figura 6 - Transcrição do professor 5 (P5)

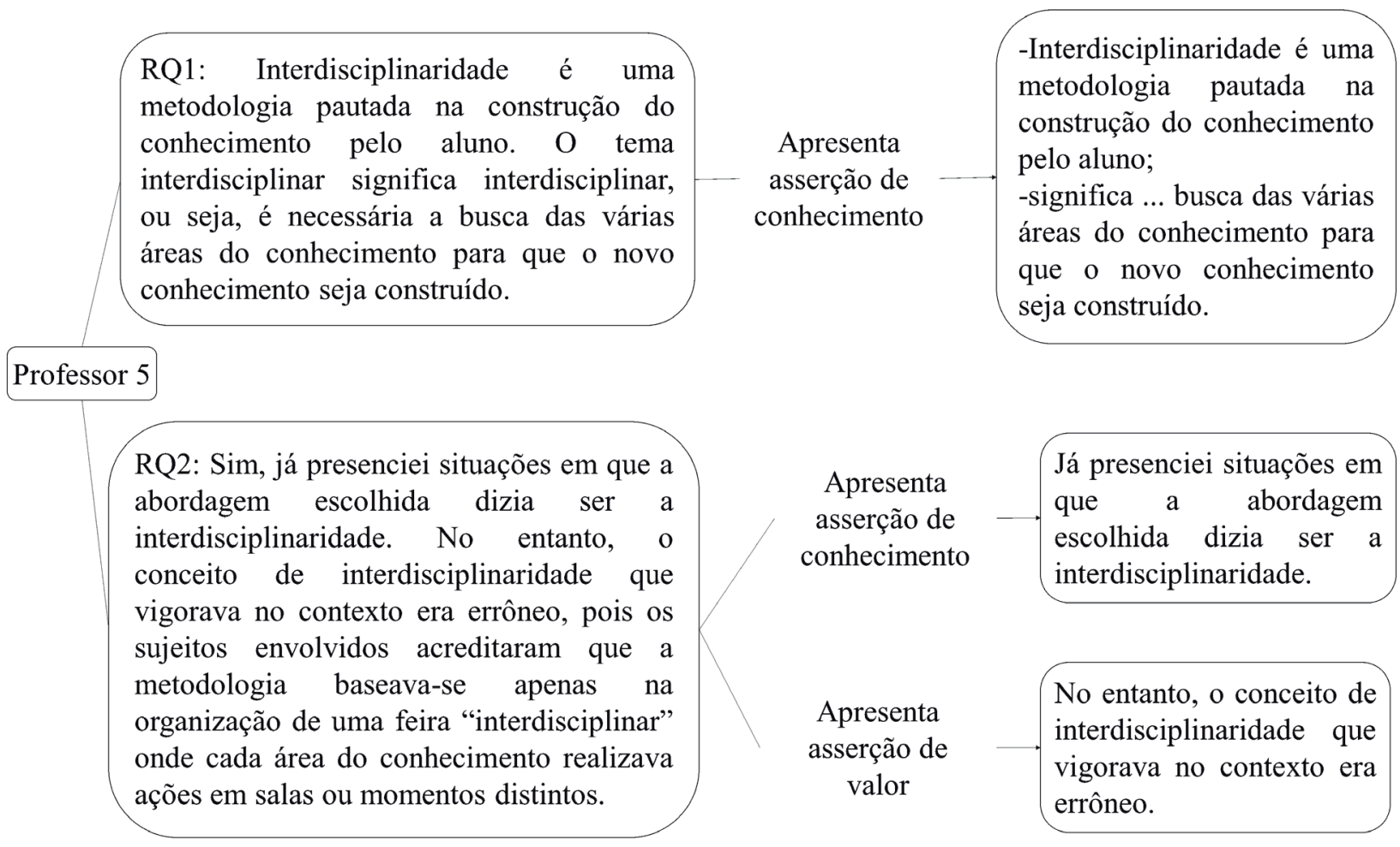

Fonte: Elaborado pelos autores

Na Q1 o sujeito associa o termo a uma atividade que envolve diversas disciplinas, ou seja, há referência à necessidade de um objetivo a ser alcançado: novo conhecimento seja construído. Este conhecimento nasce a partir do conhecimento disciplinar, porém confunde interdisciplinaridade com metodologias ativas: vê a interdisciplinaridade como uma metodologia o que indica convergência para 0 termo interdisciplinaridade.

Na Q2 relata ter vivenciado, mas não explicita quais seriam estas situações e mostra um viés negativo (erróneo). Não explicita quais as situações experienciadas. Contudo, o conceito que apresentou sobre interdisciplinaridade foi similar ao do referencial teórico, porém mostra viés negativo. Deste modo, o sujeito apresenta um viés negativo em relação à interdisciplinaridade. 
Figura 7 - Transcrição do professor 6 (P6)

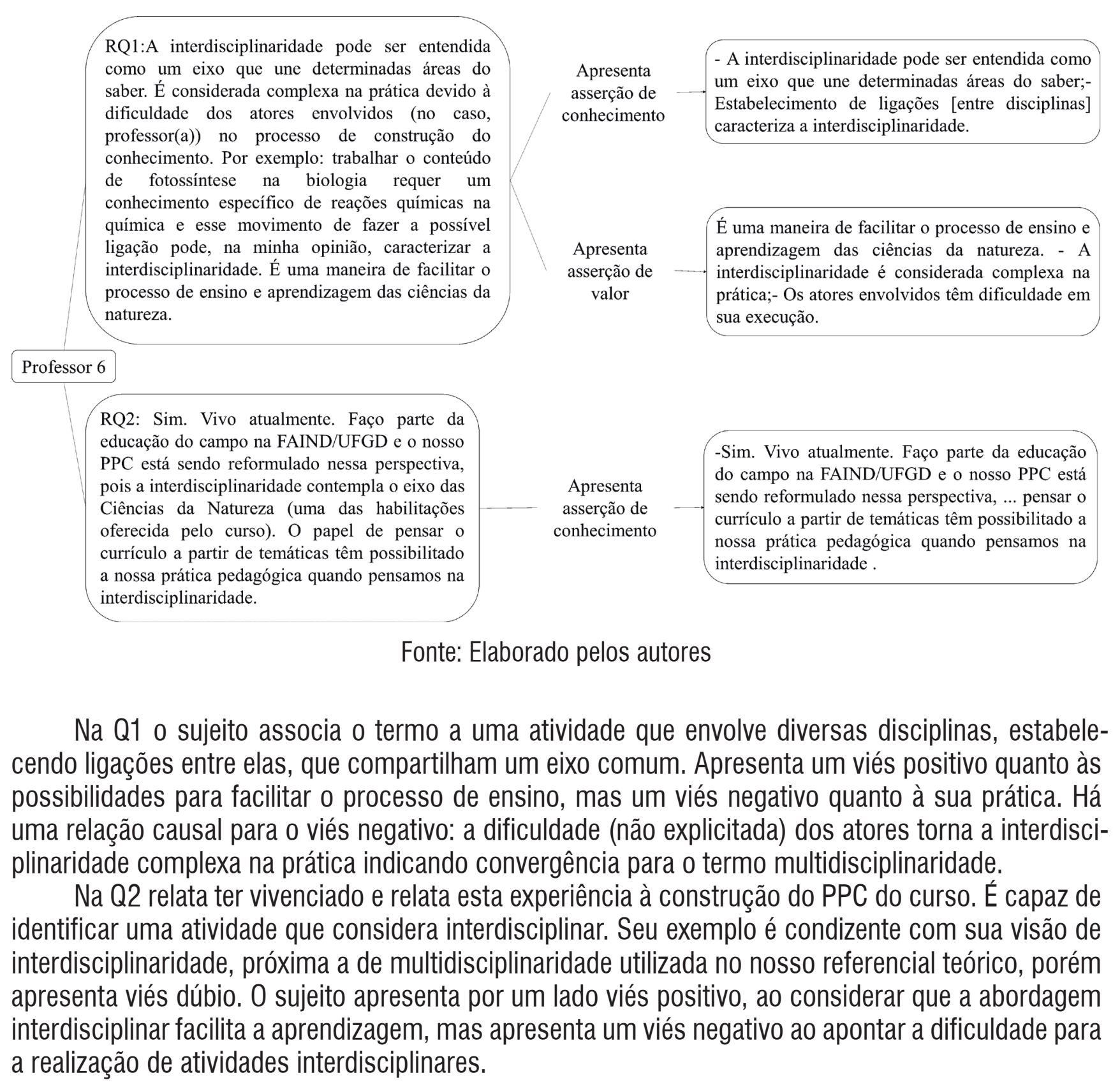

RQ1:A interdisciplinaridade pode ser entendida Q um eixo que une determinadas áreas do ática devido à envolvidos (no caso, na minha opinião, caracterizar o atualmente. Faço parte campo na FAIND/UFGD e o nosso está sendo reformulado nessa perspectiva, oferecida pelo curso). O papel de pensar o currículo a partir de temáticas têm possibilitado a nossa prática pedagógica quando pensamos na Fonte: Elaborado pelos autores
-Sim. Vivo atualmente. Faço parte da educação sendo reformulado nessa perspectiva, ... pensar o nossa prática pedagógica quando pensamos na interdisciplinaridade

Na Q1 0 sujeito associa o termo a uma atividade que envolve diversas disciplinas, estabelecendo ligações entre elas, que compartilham um eixo comum. Apresenta um viés positivo quanto às possibilidades para facilitar o processo de ensino, mas um viés negativo quanto à sua prática. Há uma relação causal para o viés negativo: a dificuldade (não explicitada) dos atores torna a interdisciplinaridade complexa na prática indicando convergência para o termo multidisciplinaridade.

$\mathrm{Na}$ Q2 relata ter vivenciado e relata esta experiência à construção do PPC do curso. É capaz de identificar uma atividade que considera interdisciplinar. Seu exemplo é condizente com sua visão de interdisciplinaridade, próxima a de multidisciplinaridade utilizada no nosso referencial teórico, porém apresenta viés dúbio. 0 sujeito apresenta por um lado viés positivo, ao considerar que a abordagem a realização de atividades interdisciplinares. 
Figura 8 - Transcrição do professor 7 (P7)

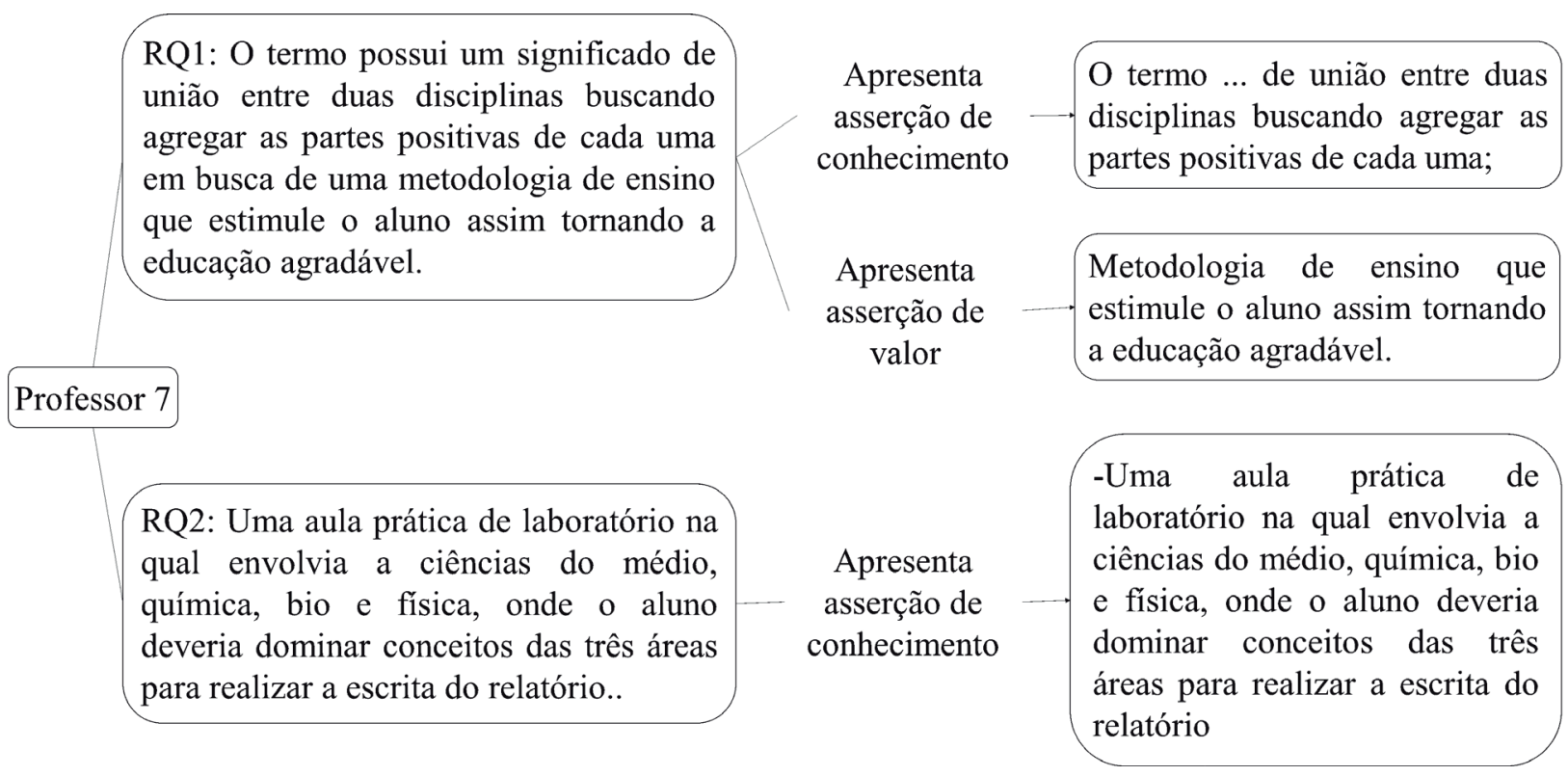

Fonte: Elaborado pelos autores

Na Q1 o sujeito associa o termo a uma atividade que envolve duas disciplinas. No entanto, não faz referência ao estabelecimento de algum tipo de relação entre elas associando interdisciplinaridade a uma metodologia de ensino. Apresenta um viés positivo e indica convergência para o termo multidisciplinaridade.

$\mathrm{Na}$ Q2 relata uma aula prática de laboratório. 0 sujeito apresenta uma definição para interdisciplinaridade que se aproxima da multidisciplinaridade. 0 exemplo apresentado tem elementos desta categoria indicando um viés positivo. 
Figura 9 - Transcrição do professor 8 (P8)

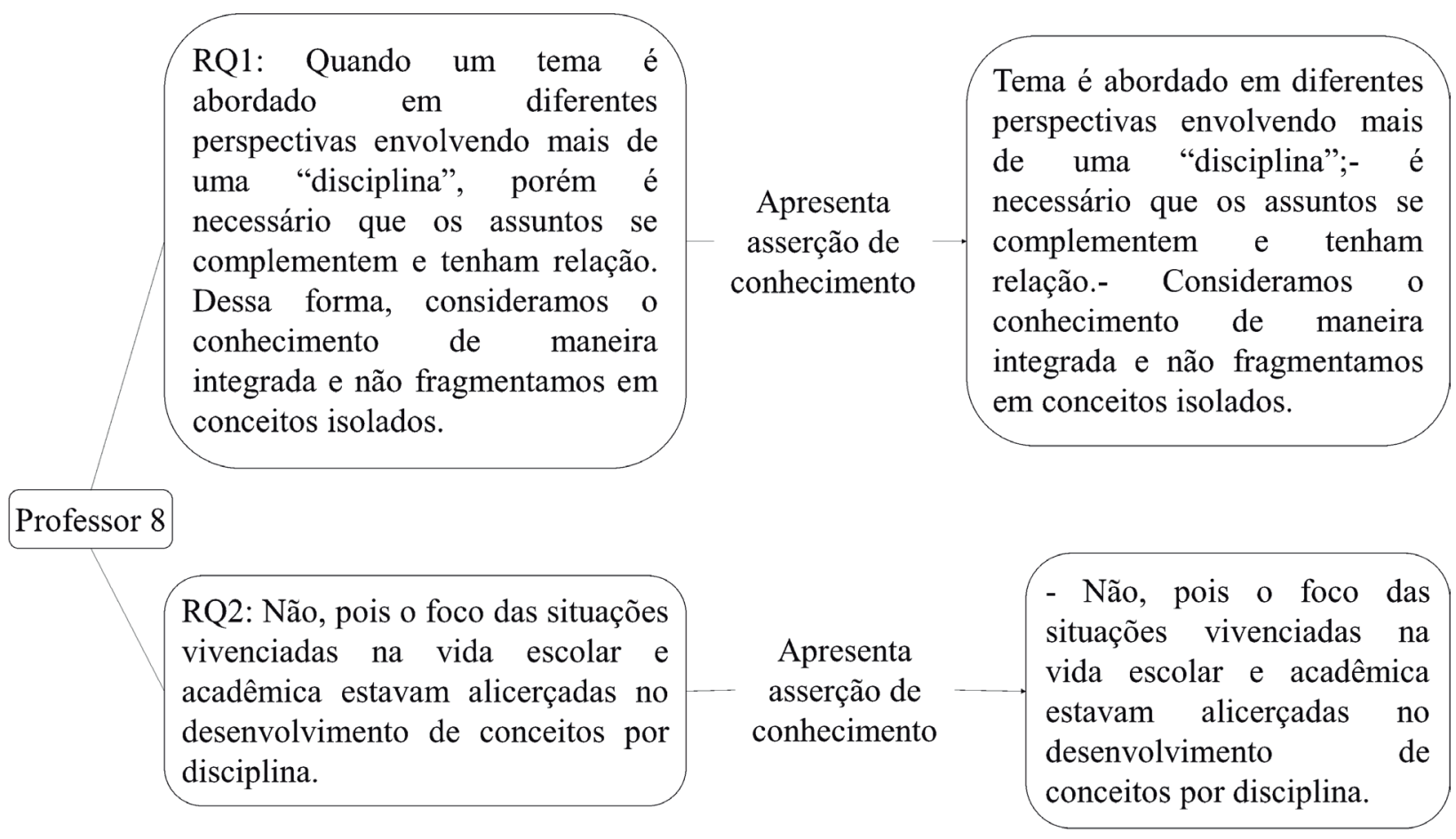

Fonte: Elaborado pelos autores

Na Q1 o sujeito associa o termo a uma atividade que envolve duas disciplinas. Contudo, há um condicionante: somente válido para disciplinas com temas próximos (correlatos). Não faz referência ao estabelecimento de algum tipo de relação entre elas, apenas a uma abordagem em paralelo, porém faz referência a uma construção integrada do conhecimento. Não há referência a um eixo ou temática comum ou a projeto condutor indicando convergência para o termo multidisciplinaridade.

$\mathrm{Na}$ Q2 relata não ter vivenciado. Deste modo não apresentou nenhum viés. 
Figura 10 - Transcrição do professor 9 (P9)

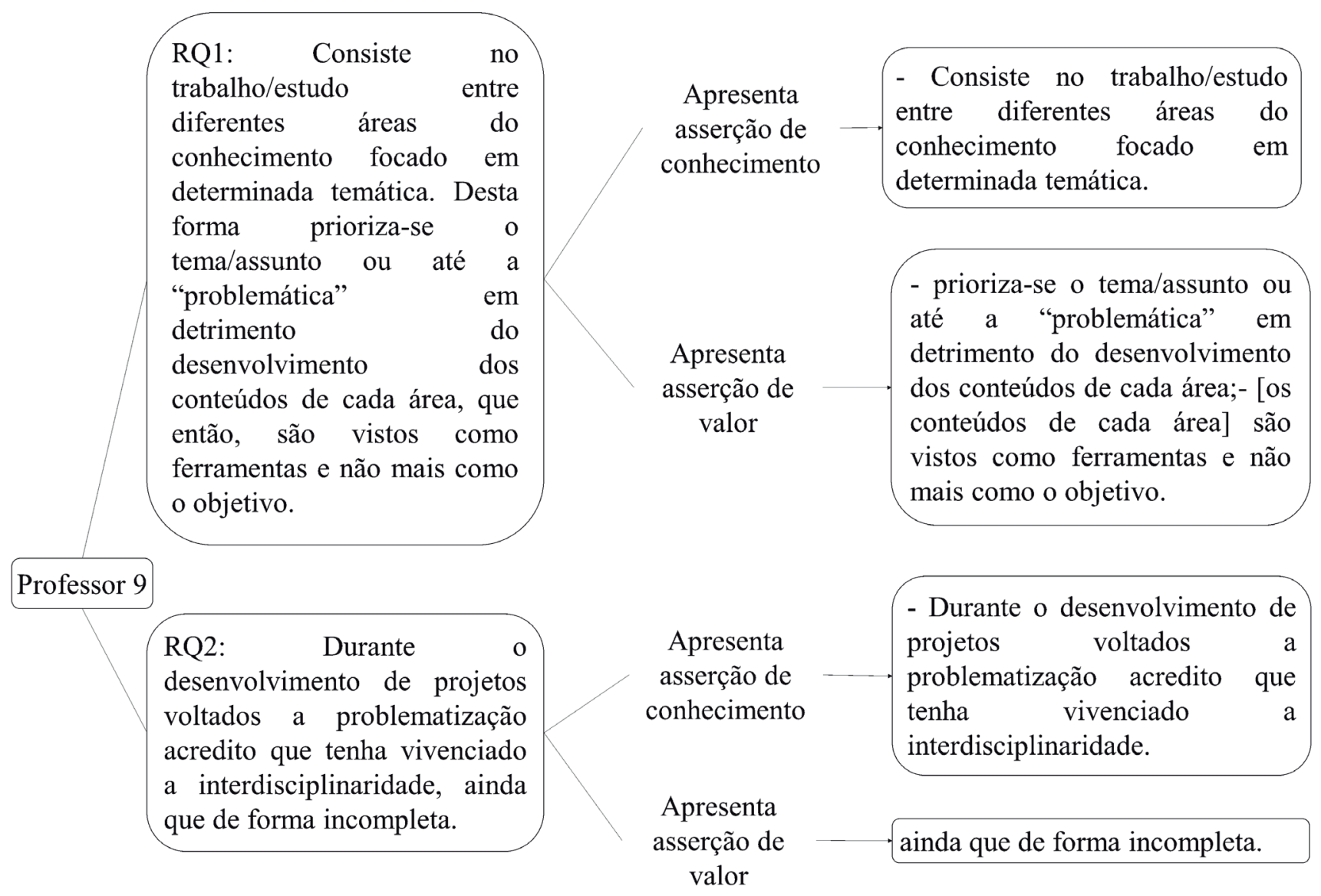

Fonte: Elaborado pelos autores

Na Q1 o sujeito associa o termo a uma atividade que envolve duas disciplinas, ou seja, há referência a uma temática comum indicando viés negativo: 0 sujeito usa a expressão "em detrimento" 0 que mostra convergência para 0 termo multidisciplinaridade.

Na Q2 relata ter vivido, mas não explicita uma situação específica (projetos voltados à problematização). 0 sujeito não explicita a natureza dos projetos, assim apresentou viés negativo indicando percepção de que não vivenciou uma experiência completa e enuncia a ideia de que as disciplinas ficam em segundo plano. 
Figura 11 - Transcrição do professor 10 (P10)

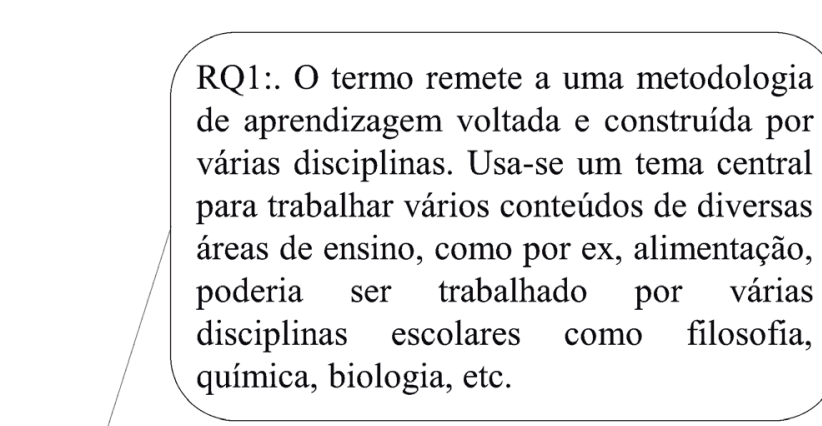

Professor 10

RQ2:. Não. Na realidade da escola é muito difícil haver essa possibilidade, o máximo que conseguimos é trabalhar projetos com 2 ou mais componentes curriculares. Isso porque para haver interdisciplinaridade deve haver um planejamento prévio de todos os professores do corpo escolar.

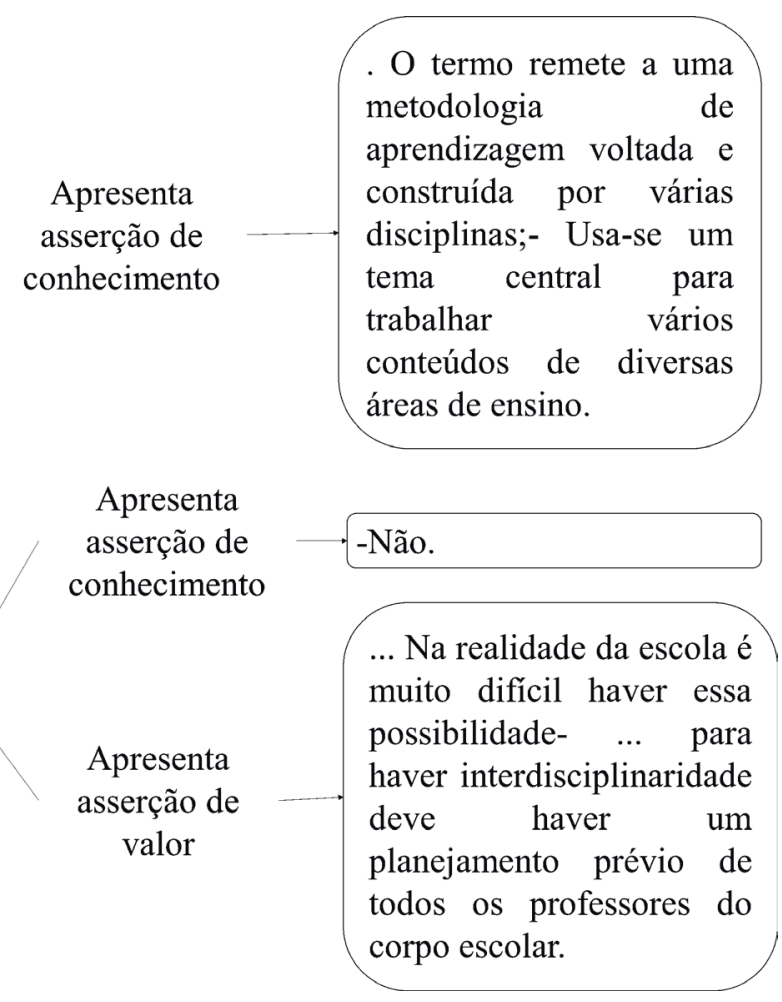

Fonte: Elaborado pelos autores

Na Q1 o sujeito associa o termo a uma atividade que envolve várias disciplinas, ou seja, há referência a uma temática comum. No entanto, não faz referência ao estabelecimento de algum tipo de relação entre elas, apenas a uma abordagem em paralelo. Associa interdisciplinaridade a uma metodologia de ensino, porém indica convergência para o termo multidisciplinaridade.

Na Q2 relata não ter vivenciado e apresenta um viés negativo (é muito difícil haver essa possibilidade). Não vê os projetos envolvendo duas ou mais disciplinas como uma atividade interdisciplinar. Não apresenta coerência entre sua visão da interdisciplinaridade, próxima de multidisciplinaridade, e o exemplo apresentado indicando viés negativo. 
Figura 12 - Transcrição do professor 11 (P11)

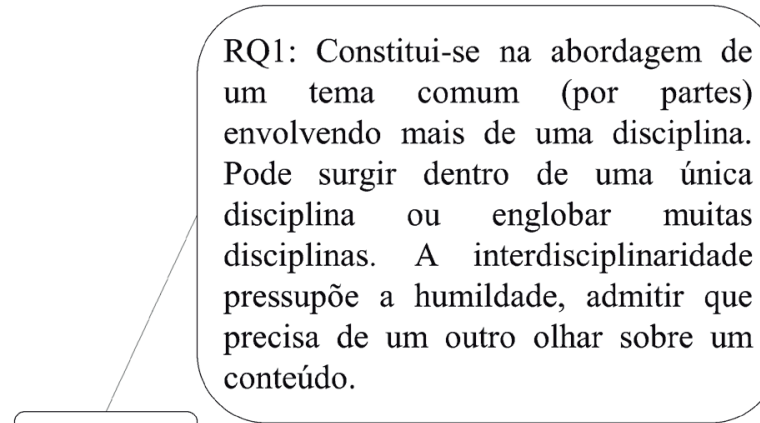

Professor 11
RQ2:A instituição que trabalho organiza seus projetos pedagógicos de forma inter, ao redor de uma pergunta condutora e como cada disciplina pode responder tal pergunta.
-Constitui-se na abordagem de um tema comum (por partes) envolvendo mais de uma disciplina.- Pode surgir dentro de uma única disciplina ou englobar muitas disciplinas. asserção de conhecimento

A interdisciplinaridade Apresenta $\quad$ pressupõe a humildade, asserção de $\longrightarrow$ admitir que precisa de um valor outro olhar sobre um conteúdo..

\author{
Apresenta \\ asserção de \\ conhecimento
}

Fonte: Elaborado pelos autores

Na Q1 o sujeito associa o termo a uma atividade que envolve várias disciplinas. Há referência a uma temática comum, ou seja, coloca como origem uma única disciplina ou envolver várias. Não faz referência ao estabelecimento de algum tipo de relação entre elas, apenas a uma abordagem em paralelo. Associa interdisciplinaridade a uma metodologia de ensino (abordagem) e exprime a opinião de que para poder ser executada, esta abordagem precisa de uma postura do professor que reconheça a necessidade de outras disciplinas para a compreensão do tema comum, porém mostra convergência para 0 termo multidisciplinaridade.

Na Q2, embora declare que a instituição desenvolve projetos interdisciplinares, o descrito é uma atividade multidisciplinar (cada disciplina pode responder tal pregunta). 0 exemplo apresentado pelo sujeito é coerente com sua visão de interdisciplinaridade, próxima à de multidisciplinaridade e este não apresenta nenhum viés. A opinião expressa não traz viés positivo ou negativo sobre a interdisciplinaridade. 
Figura 13 - Transcrição do professor 12 (P12)

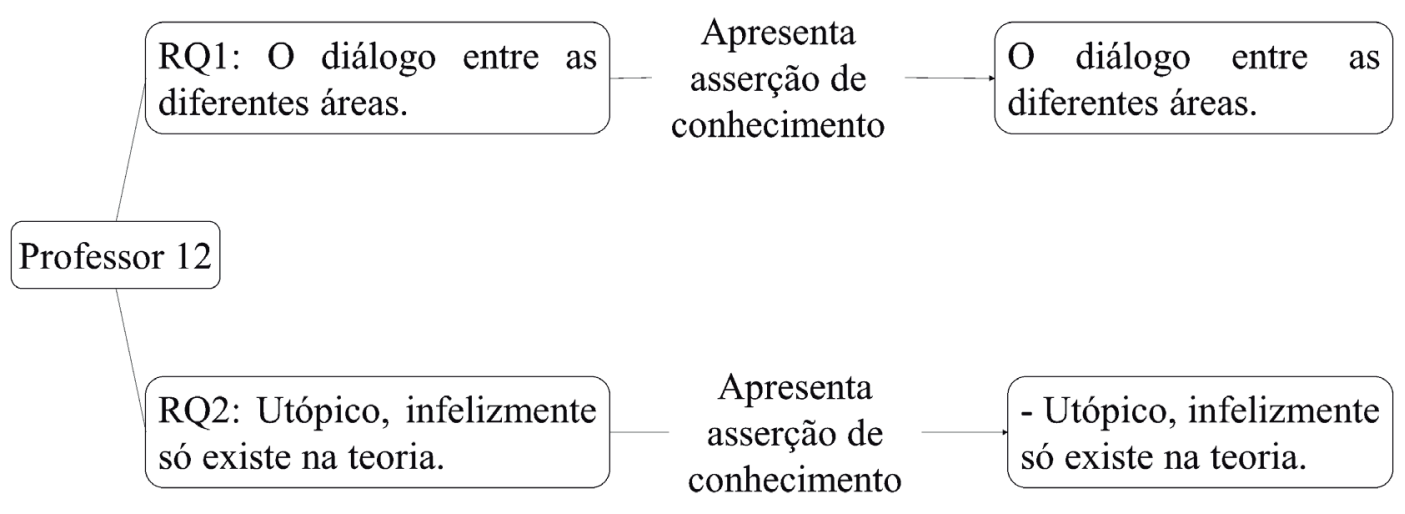

Fonte: Elaborado pelos autores

Na Q1 o sujeito associa o termo a uma atividade que envolve várias disciplinas em relação (diálogo), ou seja, não há referência a um tema comum ou projeto a ser desenvolvido. Mostrou convergência para 0 termo multidisciplinaridade.

$\mathrm{Na}$ Q2, o sujeito não declara ter vivido ou não experiência interdisciplinar indicando viés negativo. Não explicita se pensa ter vivido uma experiência interdisciplinar.

Figura 14 - Transcrição do professor 13 (P13)

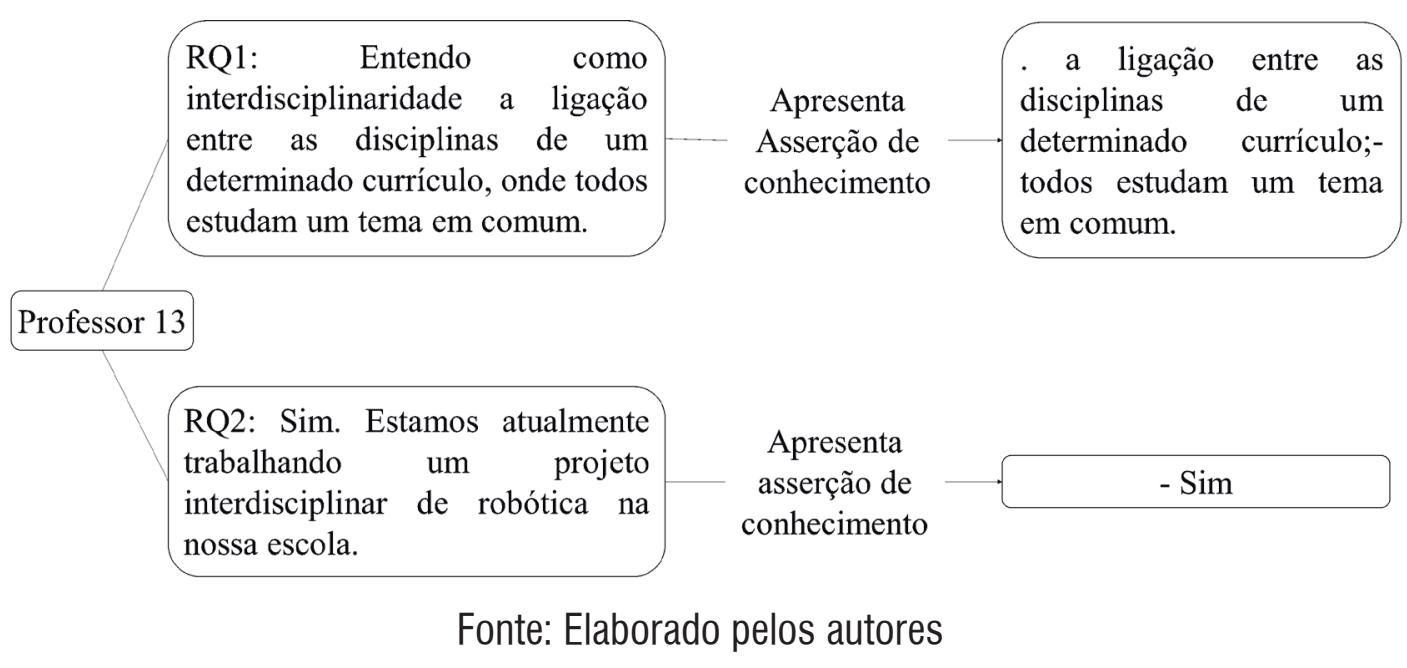

Na Q1 o sujeito associa o termo a uma atividade que envolve várias disciplinas em relação (ligação). Há referência a um tema comum, mas não a um objetivo ou projeto ou produto em comum a ser desenvolvido indicando convergência para o termo multidisciplinaridade.

Na Q2 relata ter vivido, explicita uma situação específica (projeto interdisciplinar de robótica). 0 sujeito não detalha porque o projeto de robótica seria um projeto interdisciplinar. Não apresenta nenhum viés. 
Figura 15 - Transcrição do professor 14 (P14)

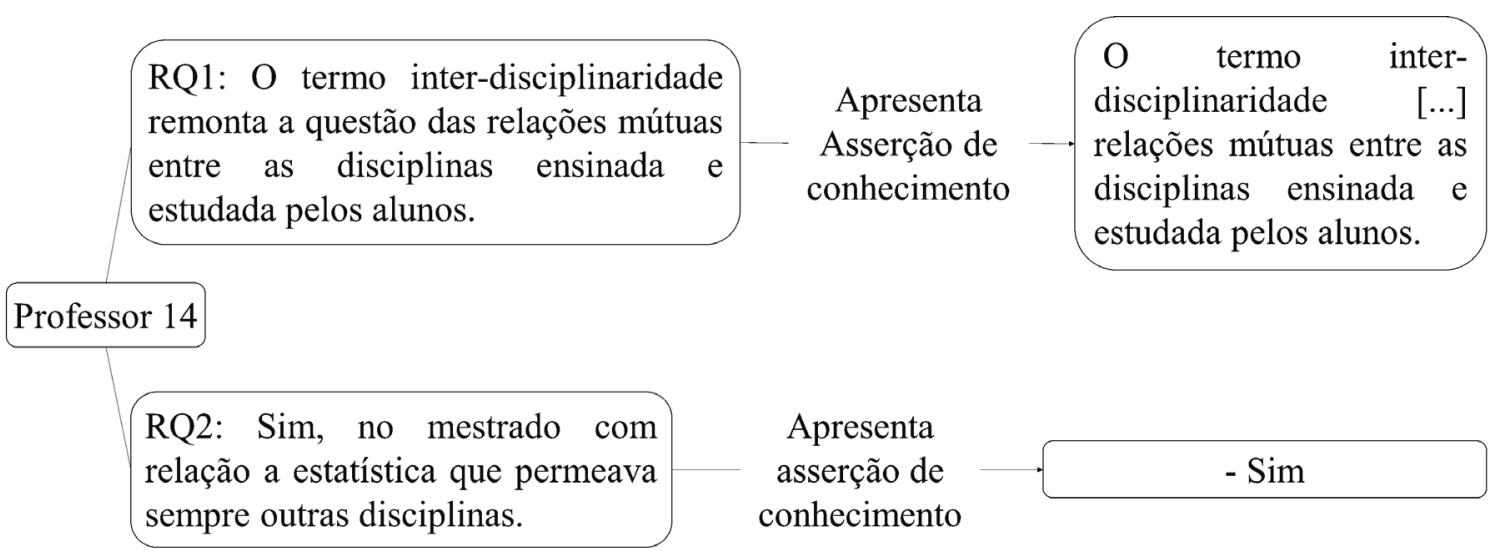

Fonte: Elaborado pelos autores

Na Q1 0 sujeito associa o termo a uma atividade que envolve várias disciplinas em relação (relações mútuas). Não há referência a um tema comum ou projeto a ser desenvolvido o que indica convergência para o termo multidisciplinaridade.

Na Q2 relata ter vivido, explicita uma situação específica (a estatística que permeava sempre outras disciplinas). De fato, o que é relatado é 0 uso de estatística como ferramenta em disciplinas com objetivos específicos. Deste modo, o sujeito apresenta um exemplo condizente com sua visão de interdisciplinaridade, próxima da de multidisciplinaridade, porém sem viés.

\section{CONSIDERAÇÕES FINAIS}

A interdisciplinaridade é assunto que muitos professores têm certa resistência e dificuldade em trabalhar em ambiente de ensino, do nível básico ao superior. Inicialmente, para muitos, discutir, entender e trabalhar a interdisciplinaridade parece ser simplesmente a junção ou a justaposição entre as várias disciplinas que compõem o referencial curricular do nível correspondente, ou um trabalho coletivo entre vários grupos ou entre disciplinas.

Os resultados oriundos desta forma de pensar a interdisciplinaridade, em sua maioria, são ações ou projetos dentro do ambiente escolar ou acadêmico com uma temática a ser abordada por diferentes disciplinas, sem que haja integração entre elas.

Neste trabalho observamos, pela análise da atividade escrita, que todos apresentaram os conceitos iniciais em relação à interdisciplinaridade e durante 0 encontro conseguiram realizar discussões acerca do conceito de interdisciplinaridade e da abordagem interdisciplinar proposta. 0 que nos leva a indícios de que foram sensibilizados em relação ao fazer interdisciplinar, pois, os professores P5 e P6 apresentaram na atividade escrita reflexões de experiências anteriores em comparação com 0 método da llha de Racionalidade Interdisciplinar.

Buscamos com base na utilização do método da construção da llha de Racionalidade Interdisciplinar proporcionar ambiente para o fazer interdisciplinar e para discussões dos conceitos que envolvem a interdisciplinaridade. Desta maneira, concluímos que as atividades desenvolvidas durante 
o encontro cumpriram com o objetivo geral proposto para este trabalho, possibilitando que os professores participantes aprofundassem o conceito de interdisciplinaridade e do fazer interdisciplinar. Ressaltamos que o processo de internalização, do interpessoal para o intrapessoal, de conceitos de qualquer natureza não se faz com rapidez, desta maneira entendemos que em relação à interdisciplinaridade e o fazer interdisciplinar, não será diferente.

\section{REFERÊNCIAS}

BRASIL. Lei n. 5.540, de 28 de novembro de 1968. Fixa normas de organização e funcionamento do ensino superior e sua articulação com a escola média, e dá outras providências. Diário Oficial da União, Brasília, DF, 28 nov. 1968.

BRASIL. Decreto-lei n. 477, de 26 de fevereiro de 1969. Define infrações disciplinares praticadas por professores, alunos, funcionários ou empregados de estabelecimentos de ensino público ou particulares, e dá outras providências. Diário Oficial da União, Brasília, DF, 26 fev. 1969.

BRASIL. Lei n05692, de 11 de agosto de 1971. Fixa Diretrizes e Bases para 0 ensino de $1^{0}$ e $2^{\circ}$ graus, e dá outras providências. Diário Oficial da União, Seção 1, p. 6377, 12 ago. 1971.

BRASIL. Lei $n^{0}$. 9.394, de 20 de dezembro de 1996. Estabelece as diretrizes e bases da educação nacional. Diário Oficial da União. Brasília, DF, Seção I, n. 248, p. 27.833, 23 dez. 1996.

BRASIL. Resolução CNE/CP 1, de 18 de fevereiro de 2002. Institui Diretrizes Curriculares Nacionais para a Formação de Professores da Educação Básica, em nível superior, curso de Licenciatura, de graduação plena. Diário Oficial da União, Brasília, Seção 1, p. 31, 9 abr. 2002.

BRASIL. Resolução CNE/CP 1, de 15 de maio de 2006. Institui Diretrizes Curriculares Nacionais para o Curso de Graduação em Pedagogia, licenciatura. Diário Oficial da União. Brasília, Seção 1, p. 11, 16 mai. 2006.

BRASIL. Resolução CNE/CEB 4, de 13 de julho de 2010. Define Diretrizes Curriculares Nacionais Gerais para a Educação Básica. Diário Oficial da União. Brasília, Seção 1, p. 824, 14 jul. 2010.

BRASIL. Conselho Nacional de Educação. Define as Diretrizes Curriculares Nacionais para a formação inicial em nível superior (cursos de licenciatura, cursos de formação pedagógica para graduados e cursos de segunda licenciatura) e para a formação continuada. Resolução CNE/CP n. 02/2015. Diário Oficial União, Brasília, Seção 1, n. 124, p. 8-12, 02 de julho de 2015.

BRASIL. Ministério da Educação. Instrumento de Avaliação de Cursos de Graduação Presencial e a Distância Autorização. Brasília: Inep, 2017a.

BRASIL. Ministério da Educação. Instrumento de Avaliação Institucional Externa Presencial e a Distância - Recredenciamento e Transformação de Organização Acadêmica. Brasília: Inep, 2017b.

BRASIL. Conselho Nacional de Educação; Câmara de Educação Básica. Resolução nº 3, de 21 de novembro de 2018. Atualiza as Diretrizes Curriculares Nacionais para o Ensino Médio. Diário Oficial da União, Brasília, Seção 1, p. 21, 22 nov. 2018. 
CHERVEL, A. L'histoire des disciplines scolaires. Réflexions sur un domaine de recherche. Histoire de l'éducation, v. 38, p. 59-119, 1988.

DAMEÃO, A. P.; ROSA, P. R. S.; ERROBIDART, N. C. G. Um método para o trabalho interdisciplinar na escola. Fórum Identidades, Itabaiana-SE, Universidade Federal de Sergipe, v. 25, p. 37-54, set./dez. 2017.

FOUREZ, G. Se représenter et mettre em oeuvre l'interdisciplinatité à l'école. Trad. Paulo Ricardo da Silva Rosa. Revue des sciences de l'éducation, v. 24, n. 1, p. 21, 1998.

GATTI, B. A. Formação de professores no Brasil: características e problemas. Educação \& Sociedade, Campinas, v. 31, n. n. 113, p. 1355-1379, out./dez. 2010.

JAPIASSU, H. Interdisciplinaridade e patologia do saber. Rio de Janeiro: Imago, 1976.

MAINGAIN, A.; DUFOUR, B.; FOUREZ, G. Abordagens Didáticas da Interdisciplinaridade. Traduzido por Joana Chaves. Lisboa: De Boeck e Larcier, 2008.

PRADO, D. S. Escolas Normais no Brasil no Período Imperial (1835-1889). Curitiba: Instituto Federal do Paraná, 2020.

RECH, J. S.; REZER, R. A Interdisciplinaridade como Fenômeno Complexo: Em defesa de sua instabilidade conceitual. RECEI - Revista Eletrônica Científica Ensino Interdisciplinar, Mossoró, v. 6, n. 17, ago. 2020.

ROSA, P. R. S. Uma introdução à Pesquisa Qualitativa em Ensino. Campo Grande: Universidade Federal de Mato Grosso do Sul, 2015.

SANTOS, A. G. F. D. et al. A formação de professores de ciências na perspectiva interdisciplinar sobre a flutuação para vida no planeta: pelos caminhos da co-docência. Revista Ensaio - Pesquisa em Educação em Ciência, Belo Horizonte, v. 21, e10596, 2019.

THIESEN, J. S. A interdisciplinaridade como um movimento articulador no processo ensino-aprendizagem. Revista Brasileira de Educação, v. 13, n. 39, p. 545-554, set./dez. 2008

TONET, I. Método Científico: Uma abordagem ontológica. 2. ed. Maceió: Coletivo Veredas, 2016.

RECEBIDO EM: 20 mai. 2021

CONCLUÍDO EM: 01 set. 2021 